\title{
Sodium valproate - can it mask neurohypophyseal diabetes insipidus?
}

\author{
Neonatal central diabetes insipidus (DI) is an uncommon disorder. It is characterised by polyuria, \\ hypernatraemia, high plasma osmolality, and low urine osmolality. Sodium valproate is a drug \\ used for seizure treatment; its use in adult patients to treat DI has been reported in the \\ literature. We report a case of neonatal neurohypophyseal DI managed with sodium valproate \\ for refractory seizures. Sodium valproate may have contributed to the improvement in DI \\ symptoms by increasing the production of antidiuretic hormone. To our knowledge, no such \\ association has been reported for neonatal DI.
}

\section{Femi Adeniyi}

ST6 Paediatrics

femi.adeniyi@nhs.net

\section{Dennis Padi}

ST5 Paediatrics

\section{Sanjeev Rath}

Neonatal Consultant

\section{Sarah Thompson \\ Neonatal Consultant}

Arrowe Park Hospital, Wirral University Teaching Hospital, Wirral

\section{Keywords}

neonatal; hypoxia; diabetes insipidus; familial; neurohypophyseal; hypernatraemia; sodium valproate

\section{Key points}

Adeniyi F., Padi D., Rath S., Thompson S. Sodium valproate - can it mask neurohypophyseal diabetes insipidus? Infant 2021; 17(4): 172-74.

1. This case of DI presented a dilemma: was it DI secondary to hypoxic ischaemic encephalopathy or familial DI?

2. Neonatologists should consider the possible effect of sodium valproate in increasing $A D H$ secretions when used to treat seizures in a neonate with DI.

\section{The case}

$\mathrm{H}$ ere, we report a case of transient neurohypophyseal DI in a late preterm female neonate. She was born at $35^{+4}$ weeks' gestation to a 31-year-old multiparous woman who presented to the local hospital with severe antepartum haemorrhage. There were no pregnancy concerns - antenatal scans and screening serology were normal - and there were no maternal risk factors for sepsis. The background maternal history included polycystic ovarian syndrome and DI, which was treated with desmopressin, an analogue of the hormone vasopressin (also called arginine vasopressin, AVP, or antidiuretic hormone, ADH) from four years of age. There were no health concerns reported in any other siblings.

The infant was delivered by an emergency caesarean section in a district general hospital for suspected placental abruption. She needed extensive resuscitation with intubation, external cardiac massage, three doses of adrenaline, $0.9 \%$ saline bolus and an emergency packed red blood cell transfusion. Her heart rate was detected to be above 60 beats per minute at 16 minutes of life with her first gasp at 29 minutes. Her venous cord blood gas analysis showed:

- $\mathrm{pH}=6.8$

- $\mathrm{pCO}_{2}=12.1 \mathrm{kPa}$

- base deficit $=-21.7 \mathrm{mmol} / \mathrm{L}$

- lactate $=15 \mathrm{mmol} / \mathrm{L}$.

She was commenced on passive cooling and transferred to the neonatal unit at the district general hospital. At two hours of age, she had seizures and required treatment with loading doses of phenobarbital and midazolam followed by a midazolam maintenance infusion, as per the local guidelines, prior to being transferred to the tertiary neonatal unit.

At the neonatal intensive care unit (NICU), she continued to have refractory seizures. She received a further loading dose of phenobarbital and escalation of the midazolam infusion. The cerebral function monitoring (CFM) was abnormal, demonstrating a burst suppression pattern with frequent spikes consistent with episodes of seizures (FIGURE 1). Her seizures finally stopped with a loading dose of phenytoin.

Haematological and biochemical laboratory parameters revealed:

- deranged coagulation on admission (prothrombin time, PT=27secs; activated partial thromboplastin time, APTT $=73$ secs; fibrinogen $=0.6 \mathrm{~g} / \mathrm{L}$; international normalised ratio, $\mathrm{INR}=2.4$ )

- thrombocytopenia $\left(67 \times 10^{\circ} / \mathrm{L}\right)$

- polycythaemia (haematocrit level=0.64)

- raised transaminase (aspartate aminotransferase test, AST=97 IU/L) and troponin $(517 \mathrm{ng} / \mathrm{L})$.

She received fresh frozen plasma and was commenced on intravenous vitamin $\mathrm{K}$. The thrombocytopenia, polycythaemia and deranged liver enzymes normalised over the course of her admission in the NICU. She was commenced on broad spectrum antibiotics following a septic screen at the district general hospital; antibiotics were discontinued at 36 hours once the blood 

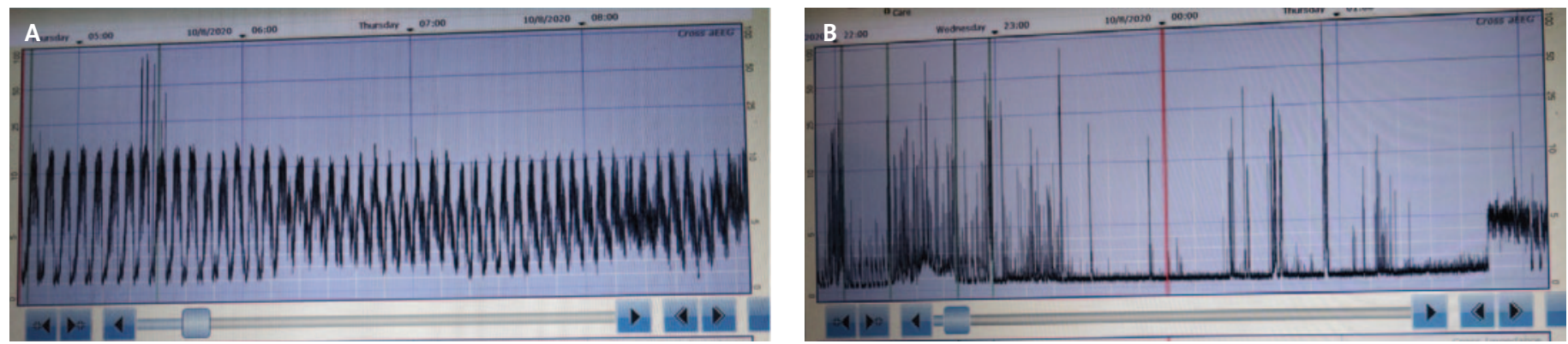

FIGURE 1 Cerebral function monitoring. A) Showing refractory seizures. B) Showing burst suppression.

culture results were negative. The UK newborn blood screen was reported as normal for sickle cell disease, cystic fibrosis, congenital hypothyroidism, phenylketonuria, medium chain acyl-Co A dehydrogenase deficiency, maple syrup disease, isovaleric acidaemia, glutaric aciduria type 1 , and homocystinuria.

During the admission at the NICU, the infant continued to have subtle seizure clusters manifesting as cycling movements of the upper and lower limbs. Levetiracetam was added for the ongoing seizure clusters but was not effective. Following discussion with the neurologist, sodium valproate was commenced and this stopped the seizures. Once seizure control was established, the levetiracetam was gradually weaned. The liver function blood tests and full blood count remained within normal ranges while the infant was on sodium valproate. Neurological examination of the infant revealed generalised hypotonia, poor suck and swallow, and an absent gag reflex. She developed severe reflux and aspiration pneumonia at around 5-9 days of admission to the NICU. She was managed with hyoscine butylbromide for excessive pooling of secretions in her oropharyngeal cavity, and Gaviscon and omeprazole for gastro-oesophageal reflux. Her feeds were given via a nasogastric tube due to the risk of aspiration.

On day four of life, she was noted to have an elevated serum sodium level of $154 \mathrm{mmol} / \mathrm{L}$. She was fluid restricted as part of the management of hypoxic ischaemic encephalopathy (HIE) and the rise in serum sodium was considered secondary to dehydration. Following liberalisation of fluid volume, her serum sodium normalised to $145 \mathrm{mmol} / \mathrm{L}$ within $24-48$ hours, only to be elevated again to $156 \mathrm{mmol} / \mathrm{L}$ on day 5 of life; at that point she was polyuric with a urine output of $6.7 \mathrm{~mL} / \mathrm{kg} / \mathrm{hour}$. Investigations showed serum osmolality of $309 \mathrm{mOsmol} / \mathrm{kg}$ with paired urine osmolality of $145 \mathrm{mOsmol} / \mathrm{kg}$ (TABLE 1).

\begin{tabular}{|c|c|c|c|c|c|c|}
\hline & \begin{tabular}{|l} 
Serum \\
sodium \\
(mmol/L)
\end{tabular} & \begin{tabular}{|l} 
Serum \\
osmolality \\
(mOsmol/kg)
\end{tabular} & \begin{tabular}{|l|} 
Urine \\
osmolality \\
(mOsmol/kg)
\end{tabular} & $\begin{array}{l}\text { Urine } \\
\text { output (mL/ } \\
\mathrm{kg} / \text { hour) }\end{array}$ & $\begin{array}{l}\text { Sodium } \\
\text { valproate } \\
\text { (mg/day) }\end{array}$ & Desmopressin \\
\hline Day 5 & 156 & & & \multirow{2}{*}{6.71} & & \\
\hline Day 5 & 148 & 309 & 145 & & & \\
\hline Day 6 & 145 & & & 3.72 & & \\
\hline Day 7 & 147 & & & & 28 & \\
\hline Day 7 & 149 & 306 & 128 & & & \\
\hline Day 8 & 147 & & & 6 & 56 & $1 \mathrm{mcg}$ \\
\hline Day 9 & 144 & 299 & 181 & 1.99 & 56 & $\begin{array}{l}\text { 1mcg three } \\
\text { times daily }\end{array}$ \\
\hline Day 10 & 141 & 290 & & 3.57 & 56 & $\begin{array}{l}\text { 1mcg twice } \\
\text { daily }\end{array}$ \\
\hline Day 11 & 141 & & & \multirow[t]{2}{*}{5.78} & 56 & $\begin{array}{l}1 \mathrm{mcg} \text { three } \\
\text { times daily }\end{array}$ \\
\hline Day 11 & 139 & 292 & 128 & & & \\
\hline Day 12 & 138 & 285 & & 1.33 & 56 & $1 \mathrm{mcg}$ \\
\hline Day 13 & 138 & 287 & 183 & 1.99 & 56 & $\begin{array}{l}\text { 1mcg twice } \\
\text { daily }\end{array}$ \\
\hline Day 13 & 136 & 292 & & & & \\
\hline Day 14 & 138 & & & 0.91 & 56 & $\begin{array}{l}\text { 1mcg twice } \\
\text { daily }\end{array}$ \\
\hline Day 15 & 138 & & & & 56 & $1 \mathrm{mcg}$ \\
\hline
\end{tabular}

TABLE 1 A timeline of laboratory investigations and drug administration.

In view of the high serum sodium (156mmol/L), high serum osmolality $(309 \mathrm{mOsmol} / \mathrm{kg})$ and low urine osmolality $(145 \mathrm{mOsmol} / \mathrm{kg})$, a diagnosis of DI secondary to HIE was considered. The case was discussed with the tertiary endocrine team who agreed with the possible diagnosis and advised commencing desmopressin. The infant's serum sodium, urine output, serum osmolality and urine osmolality subsequently normalised and desmopressin was discontinued on day 15 of life at the local hospital. We noted that sodium valproate as a seizure medication was commenced at the same time as the desmopressin.

Head magnetic resonance imaging
(MRI) showed a structurally normal brain with normal cerebellum, corpus callosum and pituitary gland. The thalami appeared to 'signal' with a higher intensity than normal. On diffusion weighted images, there were extensive areas of restricted diffusion present within the basal ganglia, lentiform nuclei and thalami with abnormal diffusion within the corpus callosum (FIGURE 2).

The infant remained in the NICU and received ventilation for six days and noninvasive ventilation (continuous positive airway pressure) for four days before being finally discharged to the local hospital on low-flow oxygen on day 14 of life. 


\section{Discussion}

Neonatal central DI is an uncommon disorder which is characterised by polyuria, hypernatraemia, high plasma osmolality, and low urine osmolality. Aetiologies discussed in the literature include central nervous system malformations, intracranial haemorrhage, intracranial infections, trauma, inflammation, HIE, and inherited mutations in coding for AVP in familial neurohypophyseal DI. ${ }^{1}$

This case presented a dilemma to the team regarding the aetiology of DI: it could be DI secondary to HIE or familial DI, as the mother had been diagnosed with DI at four years of age.

Familial neurohypophyseal DI is a rare inherited disorder with the majority inherited in an autosomal dominant pattern. A mutation in the $2.5 \mathrm{~kb}$ AVPneurophysin II (AVP-NPII) gene located on chromosome location 20p13 results in a deficiency of AVP.,3

Neonatal central DI has been linked to various aetiologies, such as congenital infections, neonatal stroke/haemorrhage, HIE, and cerebral abscess. ${ }^{4,5}$ In our index case, the diagnosis of central DI secondary to HIE was made due to the perinatal events (severe antepartum haemorrhage in the mother, poor condition at birth needing extensive resuscitation) and the further clinical course and investigations suggesting multi-organ involvement. MRI showed changes in the basal ganglia, in keeping with HIE. The presence of normal thyroid stimulating hormone (TSH), blood glucose and cortisol ( glucose $=3.5 \mathrm{mmol} / \mathrm{L} ; \mathrm{TSH}=5.64 \mathrm{mU} / \mathrm{L}$; thyroxine, $\mathrm{T} 4=21.7 \mathrm{pmol} / \mathrm{L}$; cortisol $=357 \mathrm{nmol} / \mathrm{L}$ ) and absence of other pituitary hormone levels for comment, made the diagnosis of neurohypophyseal DI secondary to HIE a likely possibility, rather than a confirmed aetiology.

Most case reports of neurohypophyseal DI have shown an abnormal pituitary gland on MRI and abnormal hypothalamic pituitary function. However, there is a case report describing similar findings to our case, ie normal pituitary gland on imaging and normal hypothalamicpituitary axis function. ${ }^{6}, 7$

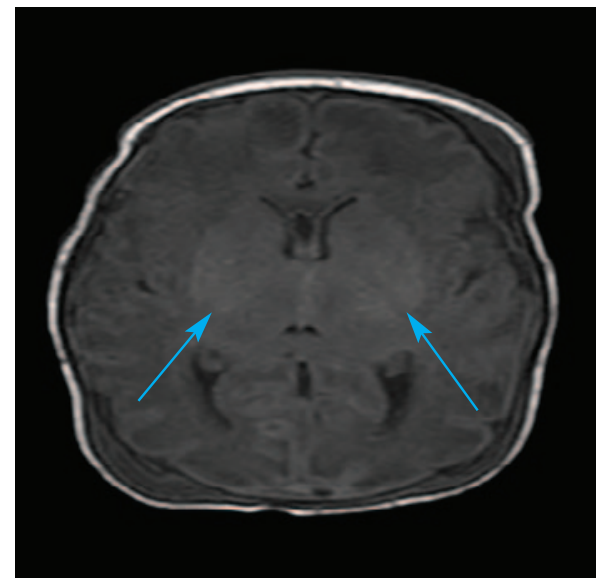

FIGURE 2 Head MRI showing extensive areas of restricted diffusion present within the basal ganglia, lentiform nuclei and thalami with abnormal diffusion within the corpus callosum

The anticonvulsive medication sodium valproate has been linked to causing hyponatraemia, attributed to increased $\mathrm{ADH}$ production in an adult case report. ${ }^{8}$ It is worth mentioning that our case was commenced on sodium valproate due to recurrent seizures, despite the use of levetiracetam. It was noted that the weaning of desmopressin since the commencement of sodium valproate was rapid. The raises the possibility that sodium valproate used in the index case could have stimulated the production of $\mathrm{ADH}$. There have also been reports of hyponatraemia and/or syndrome of inappropriate secretion of $\mathrm{ADH}$ (SIADH) in association with sodium valproate..$^{9-11}$

The index case continues to be on sodium valproate and remains off desmopressin with no symptoms of DI. Once sodium valproate is stopped, desmopressin reuse will help to establish the diagnosis of non-transient DI. A genetic test may help to differentiate the aetiology of DI in our index case and establish whether it was secondary to HIE versus familial.

\section{Conclusion}

The quick weaning of desmopressin since the commencement of sodium valproate in our case, suggests that sodium valproate may have contributed to the improvement in DI symptoms. We propose that sodium valproate can help in the treatment of DI by increasing the production of $\mathrm{ADH}$. Clinicians using sodium valproate for the management of seizures in neonates with concurrent DI need to bear in mind this potential side effect of sodium valproate.

The differential diagnosis of familiar neurohypophyseal DI cannot be ignored in our index case because of the strong family history of DI. The review of investigations (eg serum osmolality paired with urine osmolality, urine output, serum sodium, blood glucose, cortisol, thyroid stimulating hormone, adrenocorticotrophic hormone) along with detailed reporting of brain MRIs (including commenting on the pituitary gland) usually help in establishing a diagnosis of DI.

\section{Parental consent}

The authors are grateful to the parents for consenting to the writing of this case report.

\section{References}

1. Alan S, Kilic A, Cakir U, et al. 1321 The management of central diabetes insipidus in neonatal intensive care unit: experience of eight cases. Arch Dis Childhood 2012;97:A376-77.

2. Schernthaner-Reiter MH, Stratakis CA, Luger A. Genetics of diabetes insipidus. Endocrinol Metab Clin North Am 2017;46:305-34.

3. Christensen JH, Rittig S. Familial neurohypophyseal diabetes insipidus - an update. Semin Nephrol 2006;26:209-23.

4. Rivas-Crespo MF, Minones-Suarez L, G-Gallarza SS. Rare neonatal diabetes insipidus and associated late risks: case report. BMC Pediatr 2012;12:56.

5. Mohamed S, Osman A, Al Jurayyan NA, et al. Congenital toxoplasmosis presenting as central diabetes insipidus in an infant: a case report. BMC Res Notes 2014;7:184

6. Ueda H, Numoto S, Kakita H, et al. Neonatal central diabetes insipidus caused by severe perinatal asphyxia. Pediatr Ther 2016;6:278.

7. Giri D, Rath S, Babarao S. Hypothalamic pituitary axis dysfunction in a neonate with severe hypoxic ischemic encephalopathy. J Clin Neonatol 2016;5:61-63.

8. Naschitz JE, Leibovitz G. Sodium valproate correcting hypernatremia of diabetes insipidus - a fortunate incident. OJM 2018;111:817-18.

9. Sodium-valproate. Reactions Weekly 2019; 1782:287 doi.org/10.1007/s40278-019-72456-6.

10. Miyaoka T, Seno H, Itoga M, et al. Contribution of sodium valproate to the syndrome of inappropriate secretion of antidiuretic hormone. Internatl Clin Psychopharmacol 2001;16:59-61.

11. Lee HJ, Wi JK, Moon JY, et al. A case of syndrome of inappropriate scretion of anti-diuretic hormone associated with sodium valproate. Electrolyte Blood Pressure 2012;10:31-34.

\section{infant subscribe today! www.infantjournal.co.uk}

